Pre-print del artículo enviado a "Emerging Markets Finance and Trade"

Tras los cambios realizados a sugerencia de los evaluadores anónimos, el artículo fue publicado como: DíazMora, C. y García, E. (2019): "Product complexity in international production networks: comparing EU Core and Old and New EU Periphery", Emerging Markets Finance and Trade, 55(4), 950-966. https://doi.org/10.1080/1540496X.2018.1443073

\title{
PRODUCT COMPLEXITY IN INTERNATIONAL PRODUCTION NETWORKS: COMPARING THE EU CORE AND OLD AND NEW EU PERIPHERY
}

\author{
Carmen Díaz-Mora \\ Erena $\mathrm{M}^{\mathrm{a}}$ García-Lopez \\ Universidad de Castilla-La Mancha
}

\begin{abstract}
:
This paper focuses on analysing the complexity level of the basket of parts and components exported by EU countries and how it is related to trade linked to international production networks. Three blocks of EU countries, which enjoy different available comparative advantages, are distinguished (Core, New Periphery and Old Periphery). Our analysis show that more than one third of exports of P\&Cs are of very high complexity in the three blocks of countries. By estimating a panel data gravity model, we find that the higher the product complexity, the higher the volume of trade linked to international production networks, with the impact larger for the EU Core countries that exhibit a wider set of high capabilities.
\end{abstract}

Keywords: EU Core, Old EU periphery, New EU periphery, product complexity, international production networks, gravity model.

Classification JEL: F10, F14, F15, C33. 


\section{INTRODUCTION}

During the last few decades, the global economy has been exposed to a highly competitive environment with new players with clear cost advantages, encouraging the emergence of new production and organisation strategies. These include international fragmentation of production, which is characterised by the unbundling of stages of production across borders. By doing so, firms locate the different phases of the value chain in the most efficient location, i.e., where the relative costs are low and where they have a favourable environment for production. These strategies have evolved because of improvements in information, communication and transportation technologies that facilitate efficient joining of the fragments of the production process.

The result has been an expansion of international production networks (IPNs) that translate into tighter economic and trade links between countries. Although some of these networks are global, most of them show a regional bias. This bias is explained by lower transport and logistics costs and lower trade barriers from regional agreements which have often been formed between neighbouring countries (Estevadeordal et al., 2013). In the case of the European Unión, its 2004 enlargement added new players from Eastern Europe, encouraging the expansion of production networks in the region. The objective was to exploit the cost and location advantages of the new member states, just as they did with those from the southern periphery in the 1980s (Baldwin and Venables, 2013).

Cross-border production networks therefore emerge as a consequence of exploiting comparative advantages at each stage of the value chain. Firms tend to move each production stage to the most efficient location. According to literature on production fragmentation (Jones and Kierzkowski, 1990; Arnd and Kierzkowski, 2001), different stages need different technological requirements, different degrees of skilled labour and different intensity in the intermediate goods incorporated. This translates into differences in the complexity of the internationally fragmented production stages. 
Recently, a new line of research has established a connection between an economy's growth and the complexity of its products. It proposes that countries have certain comparative advantages or capabilities that determine the complexity of products made at home (Hidalgo and Hausmann, 2009; Hidalgo, 2009). Moreover, in the context of internationally fragmented production, those country capabilities would determine which production stages are domestically performed. Thus, countries involved in IPNs will have more or less complex parts of the production processes in their export basket depending on their locally available capabilities like technological, human and physical capital and logistic and organisational capability. According to Costinot et al. (2013), rich countries will be relatively better at producing more complex parts of the transnationally segmented production process, so they tend to specialize in them. These authors consider that less complex parts have a rather high labour cost share, so high-wage, high-productivity countries are less competitive in those partsi

Since countries' capabilities are not static, a dynamic dimension of countries' involvement in IPNs through upgrading can be introduced. Humphrey and Schmitz (2002) introduce this concept when they establish four types of "upgrading": process, product, functional and inter-sectoral upgrading. The first involves a more efficient transformation of inputs into outputs by reorganising the production systems or including superior technology, while product upgrading refers to the production of more complex, more sophisticated goods. Functional upgrading is related to new functions to increase the overall skill content of activities and inter-sectoral refers to moving into new productive activities. Milberg and Winkler (2010) note that, especially for manufactures, "upgrading" has been associated with companies that dynamically move a product in the value chain from one level of production to another that has activities of greater added value. This would imply that companies that participate in IPNs manage to promote themselves within the network (Cattaneo et al., 2013; Milberg and Winkler, 2010). Analysing the degree of complexity of the basket of products exported by countries not only provides us relevant information about the capabilities of the economies that produce them, but also allows us to distinguish whether an economy will be able to upgrade within the global production network. 
Because of the unavailability of statistics on the different stages of internationally fragmented production, we use trade in parts and components (P\&Cs) as a proxy for participation in IPNs, following the pioneer studies of $\mathrm{Ng}$ and Yeats (2001) and Yeats (2001). This trade is particularly appropriate for the analysis of IPNs because, given their intermediate nature, transnational exchanges of P\&Cs are necessarily destined for further processing or assembly in another country ${ }^{\mathrm{ii}}$.

The goal of this paper is to investigate, firstly, the level of complexity of the production stages that EU countries perform and export to the rest of the world and, secondly, how that level of complexity affects IPN-related trade by estimating a panel data gravity model for the period 1995-2010. We consider three groups of EU countries: the central countries (Germany, France, Italy and the United Kingdom); the old periphery (Spain, Portugal, Ireland and Greece) and the new periphery (Poland, Hungary, Slovakia and the Czech Republic). Differences in available comparative advantages between these countries seem to have stimulated the shaping of transnational production networks in the EU area. The underlying idea is that those countries with higher capabilities are able to perform more complex stages in a fragmented production process. This specialisation in more complex stages translates into the exportation of more complex components that encourage a more intensive country participation in IPNs. That is, exports of more complex components are positively associated with higher values of trade within IPNs because product complexity would indicate an upgrading position. Moreover, our analysis explores the possibility that the impact of product complexity on IPN-related trade might differ for the three EU country groups considered. In this sense, it could be expected that the effect would be particularly important for EU core countries because their high capabilities to produce more complex stages of production processes is likely a crucial factor in explaining their involvement in IPNs.

This question has hardly been addressed in the existing empirical literature on trade. To the best of our knowledge, the only related paper is Córcoles et al. (2014), who include product complexity as a determinant of export survival for the automotive industry. Using two different complexity indicators, 
the "sophistication index" proposed by Hausmann et al. (2007) and the "complexity index" developed by Hidalgo and Hausmann (2009), their econometric estimations show that the risk of interruption of trade relationships decreases with the product complexity. The authors conclude that the probability of remaining within the automotive IPNs depends on the contribution of each stage to the value chain: the greater the capabilities incorporated and so the higher the product complexity, the lower the probability of being excluded from international-scale networks in the automotive industry.

The article is organised as follows. Following this introduction, section 2 explains how product complexity is measured. Section 3 offers a descriptive analysis of the degree of product complexity of the basket of P\&Cs exported by each EU block and each country considered. In section 4, we perform the econometric analysis where the impact of product complexity on IPN-related trade is investigated. The paper ends with a section of conclusions.

\section{MEASURING THE COMPLEXITY OF PARTS AND COMPONENTS}

The concept of product complexity has only recently been introduced in the empirical literature on trade. One of the first studies was Lall et al. (2006), for whom the concept of product sophistication captures more than the technological characteristics of products, since this variable picks up factors like product differentiation, production fragmentation, availability of infrastructures, logistical needs and organisation of the value chain. These authors set out a scenario that it is free of commercial restrictions and where rich countries export products whose characteristics allow them to compete in the markets, despite their higher labour costs compared with those of developing economies. Therefore, the most developed countries would export a higher number of sophisticated products, since they are distinguished in having skilled labour, greater technological and logistical "capabilities," better infrastructures or more efficient production organisation. Thus, Lall et al. (2006) expect that a product will be more sophisticated the higher the per-capita income of the countries that export it is. 
Later, Hausmann et al. (2007) develop new indicators for measuring the degree of sophistication at the product and country levels. They note that specialising in certain productions leads to more growth than when specialising in others. With this in mind, they construct export sophistication indicators considering that some products are linked to higher levels of productivity and, consequently, it would reveal that economies that export them enjoy certain advantages, which make them more productive. The product sophistication index (PRODY) is constructed as a weighted average of the GDP per capita of the countries exporting a certain product where the weights reflect the country's revealed comparative advantage for that product. However, some authors have criticised these measures of sophistication. Sutton and Trefler (2011), for instance, note that vertical differentiation of products is not considered.

Hidalgo (2009) and Hidalgo and Hausmann (2009) consider that product complexity is related to the amount of capabilities or know-how necessary to manufacture products. These authors point out that, first, the complexity of a product is related to the (tangible and intangible) capabilities the product demands and, second, countries and products are involved in a network. They explain that economies which require a large number of capabilities for the production of a good will be economies that are more willing to adapt to changes than those that produce goods that need fewer capabilities and consequently would be less complex. Likewise, they note that the complexity of an economy is related to the characteristics of the network's structure. In this regard, it would be expected that economies with a greater range of available capabilities would participate in networks that are more complex. They develop the method of reflections where they incorporate the concepts of ubiquity and diversification based on a bipartite network structure. Ubiquity refers to the exclusivity in exporting a product, that is, whether the number of countries exporting it with a comparative advantage is low. The larger the variety of capabilities the product requires, the greater its degree of complexity will be and the smaller the number of countries that export it. Diversification refers to the number of products that an economy exports in conditions of comparative advantage, which is positively related to the 
variety of capabilities available in that country. The Method of Reflections suggests that countries with a broader set of available capabilities are more likely to have more diversified production structures, which means these countries export more exclusive products (Reinstaller et al., 2012). The Method of Reflections iteratively calculates a measure of complexity that combines both types of information, diversification and ubiquity. The Product Complexity Index (PCI) is constructed by calculating the average diversity of countries that make that product and the average ubiquity of the other products that these countries make $\mathrm{iii}^{\mathrm{ii}}$. The position of a product in the complexity ranking depends on the value of that product in the PCI. The higher the PCI value and the higher the position in the ranking (top places), the more complex the productions are.

Following previous empirical works on trade in P\&Cs as a proxy for IPN-related trade (Ng and Yeats, 2001; Yeats, 2001; Athukorala, 2005), we distinguish around one hundred commodities considered P\&Cs using 4- and 5-digit SITC levels (Table A1 of the Appendix). To analyse the degree of complexity of P\&C exports, we use PCI data from the Atlas of Economic Complexity by the Center for International Development at Harvard University, which offers a ranking of complexity by countries and products (Hausmann et al., 2011). This information is available for 200 countries, a period of 50 years and products at the 4-digit HS (Harmonized System) level (around 1,240 products) ${ }^{\text {iv }}$. Additionally, Simoes and Hidalgo (2011) develop a related tool, the Observatory of Economic Complexity by the MIT Media Lab Macro Connections group, which offers data on the PCI at the 4digit SITC (Standard International Trade Classification) level (around 770 products) and at the 4- and 6-digit HS levels (around 1,200 and 4,900 products, respectively) ${ }^{\mathrm{v}}$.

From these PCI data, we have assigned a PCI value and a position in the PCI ranking to each item of P\&Cs. To do so, we proceeded to make a correspondence between the P\&C categories of Table A1 and those categories used for PCI data. Tables A2 of the Appendix list the categories of P\&Cs sorted by their position in the ranking of product complexity in 1995 and 2010. Moreover, we display them divided into deciles of complexity. Those P\&Cs in the first decile are more complex and, consequently, 
countries require a greater number of capabilities to produce them, whereas those P\&Cs in the $10^{\text {th }}$ decile are those that require fewer capabilities and are therefore less complex. It must be noted that the different $\mathrm{P} \& \mathrm{C}$ items are distributed in the first seven deciles, i.e. no $\mathrm{P} \& \mathrm{C}$ item belongs to the last three deciles of complexity. In fact, the bulk of P\&Cs are contained in the first four deciles and, therefore, P\&Cs are productions that exhibit high and medium levels of complexity. This reveals that P\&Cs are productions that need capabilities and know-how that place them near the top and in the middle of the classification, thus demonstrating the greater complexity of these productions compared with others. It must be noted that the composition of the deciles is not fixed. The number of P\&C items in each complexity decile is different in 1995 and 2010. We observe that the P\&C items in the first, fifth and sixth complexity deciles have fallen whereas those for deciles 3 and 4 have increased.

\section{ANALYSING THE COMPLEXITY OF P\&C TRADE IN THE EU}

Considering that trade in P\&Cs is our proxy for IPN-related trade, we want to study the degree of complexity of the P\&Cs that European countries export in order to know their position and their chances of upgrading within cross-border production networks. We would expect the Core economies and, to a lesser extent, those of the Peripheries, insofar as they are advanced economies in a global context, to export $\mathrm{P} \& \mathrm{Cs}$ that require higher capabilities.

Data on trade in P\&Cs come from UN Comtrade. We analyse the complexity of the P\&C export basket of a country by calculating the share of $\mathrm{P} \& \mathrm{C}$ exports of each complexity decile in total $\mathrm{P} \& \mathrm{C}$ exports ${ }^{\mathrm{vi}}$. Figure 1 shows the structure of the $\mathrm{P} \& \mathrm{C}$ exports of each block of countries according to their degree of complexity, ordered by deciles from greater complexity (decile 1) to lesser complexity (decile 10).

In 2010, the three groups of EU countries stand out for having a greater weight of $\mathrm{P} \& \mathrm{C}$ exports in the first complexity decile: $34 \%$ for the Core economies and around $40 \%$ for both Peripheries. That is, more than one third of exports of P\&Cs are of very high complexity. Among these highly complex $\mathrm{P} \& \mathrm{Cs}$ are those related to machinery and mechanical equipment, road vehicles and some branches of 
electrical equipment. Moreover, the bulk of exports of P\&Cs consists of highly complex goods, since more than two thirds of them belong to the three first complexity deciles. If we treat this data as indicative of high complexity, then the New Periphery would be the EU area with a more complex basket of exported P\&Cs: almost 80 per cent of exported P\&Cs are in the three first complexity deciles, followed by the Core economies (70 per cent) and the Old Periphery (63 per cent). This sorting by complexity would be similar if the sum of deciles 1 and 2 would be chosen as indicative of high complexity. In any case, our data confirm the high degree of complexity of P\&Cs exported by EU countries.

\section{$\{$ Figure 1\}}

Between 1995 and 2000, we observe some changes in the distribution of P\&Cs exports by deciles of complexity. Starting with the Core economies, the highly complex P\&C exports (specifically those belong to deciles 1 and 2) have experienced a decrease in their share in total P\&C exports in favour of those included in deciles 3 and 4 . Here it is important to note that those changes are totally due to the changes in the degree of complexity assigned by the Atlas of Economic Complexity to each P\&C item. As explained above, the number of $\mathrm{P} \& \mathrm{C}$ items that belong to the first decile has reduced whereas those from the third and fourth deciles have increased. If the composition of the complexity deciles had not changed between 1995 and 2010, the structure of P\&C exports by complexity deciles would hardly have been altered. This fact is illustrated in Figure A.1 of the Appendix where the structure of P\&C exports using the composition of complexity deciles for 2010 is represented in two columns. The second column is the same than that of Figure 1, that is, it represents the structure of P\&C exports in 2010 which is calculated using the complexity deciles for 2010. The first column represents the structure of P\&C exports in 1995 using also the complexity deciles for 2010. As can be observed, both are very similar, reinforcing the conclusion that the changes in the structure of $\mathrm{P} \& \mathrm{C}$ exports by 
complexity deciles between 1995 and 2005 are mainly explained by the changes in the composition of the complexity deciles.

The decrease in the share of exports of very high complex P\&Cs (those belong to the first decile) does not occur in the other two European blocks (Figure 1). It has essentially remained stable in the New Periphery and it shows an advance in the Old Periphery. Furthermore, when the sum of the three first deciles is considered as an indicator of high complexity, we observe an increase in the share of P\&C exports of high complexity for both areas, and this increase is more pronounced for the Old Periphery. Unlike the Core economies, these changes would have taken place even if the composition of the complexity deciles hadn't been altered (Figure A.1. of the Appendix).

Considering the countries that comprise the EU core block (Figure 2), we observe a high similarity between France, Germany and Italy, where around 40 per cent of P\&C exports are of very high complexity (those belonging to the first decile) and around 70 per cent are of high complexity (those belonging to the three first deciles) in 2010. The exception here is the United Kingdom, where those figures are significantly lower and, conversely, the share of $\mathrm{P} \& \mathrm{C}$ exports in decile 4 is larger. As for the whole Core block, the four countries show a decrease in the share of exports in deciles 1 and 2 in favour of those in deciles 3 and 4 between 1995 and 2010. And, again, this is mainly explained by the changes in the composition of the complexity deciles.

\section{$\{$ Figure 2\}}

Within the countries of the New Periphery, the share of P\&C exports of the highest complexity (decile 1) in 2010 ranges from almost 35 per cent in Hungary to 45 per cent in Poland. When deciles from 1 to 3 are considered as high complexity, the share of $\mathrm{P} \& \mathrm{C}$ exports of high complexity is over 80 per cent in all of them, except the Czech Republic. Regarding changes in P\&C export structure by complexity deciles over time, different evolutions are observed depending on the country. The only common point is that all of them show a rise in the share of $\mathrm{P} \& \mathrm{C}$ exports of complexity deciles 3 and 
4. However, whereas the Czech Republic and Hungry maintain the share of exports of the highest complexity (decile 1), Poland increases it and Slovakia severely reduces it. These results can be interpreted as a shift towards more complex $\mathrm{P} \& \mathrm{C}$ exports and an upgrading in the involvement in global value chains in the case of Poland and the opposite in the case of Slovakia. These changes would be even clearer if we calculated the export structure by complexity deciles without considering changes in the composition of the complexity deciles between 1995 and 2010 (Figure A.1 of the Appendix). In that case, the Czech Republic and Hungary do raise the share of more complex P\&Cs in their export basket and Poland does it in a more pronounced way. For Slovakia, the decrease in the weight of more complex P\&Cs in its export basket occurs regardless of the composition of the complexity deciles.

Lastly, we observe a high heterogeneity in the $\mathrm{P} \& \mathrm{C}$ export structure by complexity between countries that make up the Old Periphery. If we focus on the highest complexity level (decile 1), Spain and Portugal concentrate around the half of their $\mathrm{P} \& \mathrm{C}$ exports in more complex $\mathrm{P} \& \mathrm{Cs}$, while in Greece and Ireland, the percentages are drastically lower (10 and 5 per cent, respectively). This highest complexity decile includes most of the $\mathrm{P} \& \mathrm{Cs}$ of the automotive industry, in whose global value chains these countries most actively participate. When the three first complexity deciles are used as indicative of high complexity, the country ranking by complexity remains similar: the share of high complex P\&Cs is around 80 per cent for Spain and Portugal, it is below 50 per cent for Greece and it is around 20 per cent for Ireland. This low figure for Ireland is accompanied by a strong concentration of its $\mathrm{P} \& \mathrm{C}$ exports in those of decile 4 complexity (around 80 per cent of total $\mathrm{P} \& \mathrm{C}$ exports). This is explained by the importance that $\mathrm{P} \& \mathrm{Cs}$ of electrical equipment have in Irish exports. By focusing on changes over time, like in the countries of the other two blocks, the share of P\&C exports of complexity deciles 3 and mainly 4 increases. The rise is particularly large for Ireland and for Greece. In Greece and Spain, those changes take place in detriment of the share of more complex P\&Cs, namely deciles 1 and 2. Except for Ireland, these changes basically maintain regardless of the composition of the complexity deciles. So, changes in that composition are only partially responsible of the changes in 
$\mathrm{P} \& \mathrm{C}$ export structure by complexity. An interesting evolution is exhibited by Portugal, where a strong increase in the export share of $\mathrm{P} \& \mathrm{Cs}$ in the highest complexity level is observed. This rise is exclusively due to a higher export growth of these more complex P\&Cs compared with other P\&Cs because it would be similar if the complexity deciles hadn't been altered (Figure A1. of the Appendix).

\section{EMPIRICAL MODEL}

We propose estimating a gravity model to study how product complexity is related to trade in P\&Cs, that is, trade associated with IPNs for the 12 EU countries studied here. The gravity model is a widely used tool for explaining bilateral trade flows. It estimates the volume of bilateral trade according to the size of the economies involved and the costs these flows entail, costs that depend on variables like distance, belonging to preferential agreements or common language.

The specification of the (expanded) gravity model that we propose is the following:

$\ln \mathrm{X}_{\mathrm{ijt}}=\beta_{\mathrm{o}}+\beta_{1} \operatorname{lnGDP}_{\mathrm{it}}+\beta_{2} \operatorname{lnGDP}_{\mathrm{jt}}+\beta_{3} \operatorname{lnDistance}_{\mathrm{ij}}+\beta_{4}$ Colony $_{\mathrm{ij}}+\beta_{5}$ Contiguity $_{\mathrm{ij}}+\beta_{6}$ Common_Language $\mathrm{ij}_{\mathrm{ij}}+\beta_{7} \mathrm{EU}_{\mathrm{ijt}}+\beta_{8} \operatorname{lnDiff\_ GDPpc} \mathrm{ijt}_{\mathrm{j}}+\beta_{9} \mathrm{PCI}_{\mathrm{pt}}+D_{\mathrm{s}}+D_{\mathrm{t}}+D_{\mathrm{i}}+D_{\mathrm{j}}+\varepsilon_{\mathrm{ij}}$

where $X^{p}{ }_{i j t}$ is the dependent variable that denotes the nominal exports of each $\mathrm{P} \& \mathrm{C} p$ from country $i$ to country $j$ in year $t$. That is, exports of each P\&C from the 12 EU countries analysed to their main trading partners (90 countries) and the exports of these 90 countries to the $12 \mathrm{EU}$ economies (including trade between the 12 EU members) for the period 1995-2010. The partner countries are listed in Table A3 of the Appendix. We estimate the model using OLS.

Next, we justify each of the explanatory variables included in the model. The definition and statistical sources of these variables are reported in Table A4 of the Appendix. Our explanatory variable of interest is the product complexity index of each $\mathrm{P} \& \mathrm{C} p$ for each year of the period $1995-2010\left(P C I_{p t}\right)$. Additionally, we measure product complexity using PCI data only for 1995, in order to address potential endogeneity problems since both the dependent and the explanatory variables are constructed 
using foreign trade data that vary by year, by product and by country. Furthermore, export data for 1995 are excluded in these estimates.

We control for the size of the trading economies using their GDP $\left(G D P_{i t}\right.$ and $\left.G D P_{j t}\right)$. We expect their sign to be positive, since the larger the economy is, the higher the volume of trade in P\&Cs is. The variable Distance $_{i j}$ refers to the geographical distance between countries. We presume that the shorter the distance is, the more trade in P\&Cs there will be. Likewise, we expect that a common colonial past, sharing the same language or having a common border (Colony $y_{i j}$, Common_language $i j$, and Contiguity $_{i j}$ ) will favor $\mathrm{P} \& \mathrm{C}$ trade, because the transaction costs of trade associated with IPNs will be lower. We expect the same positive impact for being partners in a regional integration agreement, in this case, the EU $\left(E U_{i j t}\right)$.

We expand the basic gravity model by incorporating an additional variable that captures other factors that influence trade within IPNs. This variable is the absolute differences in GDP per capita among the trading countries (Diff_GDPpc $\left.c_{i j t}\right)$. Although IPNs usually requires the existence of different comparative advantages among the partner countries (Jones and Kierzkowski, 2001), these differences cannot be too large in order to ensure the proper functioning of the cross-border production sharing (Blázquez et al., 2012).

We also incorporate sectoral and time dummies. Sectoral dummies $\left(D_{s}\right)$ are included to control for specific characteristics of industries in order to capture which productions participate in IPNs more or less intensely. These sectors are defined on the basis of the divisions that comprise Section 7 of the SITC-Rev.3. We add temporal dummies $\left(D_{t}\right)$ to capture the impact of the factors common to all the economies and which are specific to each year of the period studied.

Furthermore, to control for unobserved multilateral trade resistance, we estimate the model, including exporter and importer fixed effects $\left(D_{i}\right.$ and $\left.D_{j}\right)$. As Anderson and van Wincoop (2003) point out, the volume of trade between any two countries depends not only on the costs of bilateral trade (bilateral 
trade resistance), but also on these bilateral trade costs relative to the cost of trade with other economies (multilateral trade resistance). Ignoring multilateral trade resistance may lead to biased estimates. Following Anderson and van Wincoop (2004), including time-varying exporter and importer dummies would be a better choice for panel data because they capture time-varying multilateral trade resistance. Hence, as a robustness check, we use time-varying exporter and importer dummy variables $\left(D_{i t}\right.$ and $D_{j t}$ ), then eliminate other time-varying country variables from the model such as exporter and importer GDPs. Additionally, these country dummies would capture any country characteristic that might influence trade in P\&Cs.

Another methodological issue concerns the treatment of zero trade flows in the sample. To deal with it, we use the two-stage procedure developed by Helpman et al. (2008) (hereinafter HMR). HMR incorporate the presence of fixed costs of exporting and heterogeneity in productivity across firms (insights of the new-new trade models) into the gravity framework. Their estimation procedure makes it possible to correctly treat the observations with a value of zero, as they capture the existence of those two factors (fixed costs of exporting and firm heterogeneity) while capturing the firm's decision to export or not. HMR start with a two-stage model, where the first stage is a Probit model that specifies the possibility that country $j$ exports to country $i$ as a function of observable variables. This is how we predict the components of that first equation that will be used in the second stage, to be able to estimate the model in its linearizable form. In the estimation that constitutes the second stage, it is important to take into account that the regressors might have different effects on the extensive trade margin (impact on changes in the number of companies that trade) or on the intensive trade margin (impact on changes in the volume of company exports). The authors propose common religion and language as the variables to exclude, the first one being the one we have determined as the variable of exclusion in our paper.

Because of the complexity of the calculation of the second stage, HMR develop an approach with a non-parametric, flexible functional form. To do this, they make partitions of the predicted probability 
of exporting from $j$ to $i$ into equally sized bins. The results that they obtain in the comparison of both processes are similar with regard to sign and statistical significance, even though the coefficients might have a lower value, so this non-parametric approach is considered an ideal alternative.

In our model, because of the significant number of fixed country effects generated, the estimation of the second stage in the model by HMR produces problematic results because of the size of the base (Dür et al. 2014), so we have chosen to apply the non-parametric approach proposed by HMR (2008). To do this, we proceeded to divide our database into 20 bins, each of which must contain the same number of observations. This way, the same indicator can be assigned to all the observations that make up each of the 20 bins and incorporated in the second stage, so that the model can be estimated in its linear form. We have estimated this approach via bins, with the number of bins higher and lower than 50 and 100, without changing the sign or the significance of the variables, although the coefficients of the variables shrink in value as the number of bins established increases.

\section{Estimation Results}

Table 1 displays the results of the estimations. Column 1 lists the results when incorporating the degree of complexity of each $\mathrm{P} \& \mathrm{C} p$ for each year $\left(\mathrm{PCI}_{\mathrm{pt}}\right)$ as a factor that is related to trade within IPNs. As for the PCI $\mathrm{pt}_{\mathrm{pt}}$ variable, its positive and statistically significant coefficient indicates that the level of complexity of the P\&Cs exported is positively related to the volume of trade within IPNs. That is, the greater the value the PCI takes, and therefore the higher the complexity of the P\&Cs, the more trade in $\mathrm{P} \& \mathrm{Cs}$ among partner countries. This confirms our hypothesis that higher complexity of P\&Cs is associated with larger IPN-related trade.

This trade is positively related to the size of the trading economies, and to sharing language and colonial ties as well. Likewise, the volume of trade will also be greater between EU members. However, trade in $\mathrm{P} \& \mathrm{Cs}$ is negatively correlated with geographical distance and economic distance (measured by differences in GDPpc) between countries. 
Regarding industry dummies, we find that trade in P\&Cs of division 75 (office machines and automatic data processing machines) is significantly greater than that of the other branches. Other divisions with larger trade in P\&Cs are 77 (electrical machinery, apparatus and appliances) and 78 (motor vehicles), with division 79 (other transport equipment) as the reference. Hence, in the country and period sample of our study, those manufacturing industries are where production processes are most internationally fragmented and trade within IPNs is more active. The remaining divisions show less trade in P\&Cs than the reference industry group.

In the following columns, to mitigate potential endogeneity problems, we use PCI data only for 1995 and export data for that year are excluded from the estimations. The results, which are displayed in column (2), hardly change. The complexity of the P\&Cs exported is positively related to the volume of trade within IPNs, although the coefficient is smaller than the corresponding coefficient in column (1).

\section{$\{$ Table 1\}}

In column (3), we add three country-group dummies for capturing the behaviour of the EU country blocks. Specifically, these dummy variables seek to control, respectively, for the importance that the Core, Old Periphery and New Periphery countries have in world trade in P\&Cs. For example, the Core dummy takes the value 1 when the countries that comprise the Core are importers or exporters of P\&Cs and zero otherwise. Similar dummies are constructed for Old and New Peripheries. The positive sign and the statistical significance of the Core countries dummy suggest that trade within IPNs is significantly more intensive in the EU Core countries than in other countries. This fact reflects that the group of economies that comprise the EU Core are particularly active participants in the strategy of international production fragmentation. On the opposite side are both Peripheries, in line with the negative (and significant) coefficients of both country group dummies. This is particularly true for the 
Old Periphery block. The remaining variables of the model show coefficients similar to those obtained in column (2).

In Column 4, we add the interactions between the complexity variable and the dummies for EU countries groups into the model. Our aim here is to know whether the complexity of P\&Cs differentially affects trade within IPNs depending on the EU country group considered (Core, Old Periphery and New Periphery). Regarding the coefficients of the interactions, it is observed that the interaction between the PCI variable and the Core countries dummy is statically significant and takes a positive sign. That is, the positive relation between product complexity and trade in P\&Cs is more pronounced for Core EU economies. This highlights that for these central EU economies, the greater $\mathrm{P} \& \mathrm{C}$ complexity is a particularly favourable characteristic for their participation in IPNs. The interaction coefficient could also be interpreted to mean that the Core countries' greater trade in P\&Cs reflect more IPN-related trade, more so when P\&Cs are more complex. On the opposite side are both Peripheries, whose interactions with the complexity variable show a negative and statistically significant coefficient. Hence, the positive relation between product complexity and trade in P\&Cs is less pronounced for these EU peripheral countries. Put another way, the lesser importance of the periphery countries in trade within IPNs is mitigated when P\&Cs are less complex.

Unlike previous columns, where multilateral resistance is controlled for using exporter and importer fixed effects, in the last three columns of Table 1 we include time-varying exporter and importer dummies. The results are, however, very similar. The greater the product complexity, the greater the value of trade in $\mathrm{P} \& \mathrm{Cs}$, with the effect more pronounced for EU core countries.

We test the robustness of these results by using alternative estimation methods. Specifically, we estimate the model using HMR's two-step estimation procedure (Table 2). As explained above, this technique tries to correct the sample selection bias resulting from eliminating zero trade flows when estimating the logarithmic form of the gravity equation and the bias caused by unobserved firm 
heterogeneity. We report the results of the second stage of the two-step estimation procedure that consists of a gravity equation estimated in logarithmic form ${ }^{\mathrm{vii}}$. All the explanatory variables maintain the sign and statistical significance. We again find a positive relationship between product complexity and volume of trade within IPNs (all columns), which is more pronounced for the EU Core block (column 3). These findings are similar when using exporter and importer fixed effects (columns 1 to 3) and when using time-varying exporter and importer dummies (columns 4 to 6).

\section{$\{$ Table 2$\}$}

We also estimate the augmented gravity model using the Poisson Pseudo Maximum Likelihood (PPML) estimator. Santos Silva and Tenreyro (2006) propose the use of the PPML technique to deal with zero-valued trade flows in estimating the gravity equation. Additionally, it is able to take account of observed heterogeneity. However, like other methods for estimating the gravity equation, the PPML has some limitations and, therefore, that it can be outperformed by other estimators in some cases. In fact, there is no consensus on what the best performing estimator is (Kareem et al., 2016). The results, which are reported in Appendix Table A.5, are in line with our prior findings: trade within IPNs increases with product complexity. Although these estimates show positive interaction terms for the three EU blocks, the positive effect of product complexity is particularly pronounced for EU core countries.

\section{CONCLUSIONS}

In this paper, we study how the degree of product complexity is related to trade linked to international production networks. The three blocks of countries exhibit a high degree of complexity of the basket of P\&Cs exported. Two facts support this: more than one third of exports of P\&Cs are of very high 
complexity (first decile of complexity) and more than two thirds belong to the first three complexity deciles, with complexity particularly high for the EU New Periphery block.

By estimating a panel data gravity model, we find that trade in P\&Cs, which is used as a proxy of IPNrelated trade, increases with the degree of product complexity: the higher the product complexity, the higher the volume of IPN-related trade. Moreover, our results show that the EU Core countries are particularly active in this IPN-related trade, suggesting that they are active participants in the strategy of international fragmentation of production. Furthermore, we explore whether the impact of the product complexity differs for the three blocks of the EU countries and we find that it is so. For the EU Core countries, the positive relation between product complexity and IPN-related trade is even more pronounced. The fact that the Core countries are economies with a broader set of high capabilities could help to explain this larger positive correlation.

\section{References:}

ANDERSON, J.E. and van WINCOOP, E. (2003): "Gravity with Gravitas: A Solution to the Border Puzzle", American Economic Review, vol. 93, 170-192.

ANDERSON, J.E. and van WINCOOP, E. (2004): "Trade Costs", Journal of Economic Literature, vol. 45, 691-741 
ARDNT, S. and KIERZKOWSKI, H. (2001): "Fragmentation: New Production patterns in the World Economy", Oxford University Press, Oxford.

ATHUKORALA, P. (2005): "Product fragmentation and trade patterns in East Asia", Economic Paper, vol. 7 (3), 233-256.

BALDWIN, R. and VENABLES, A.J. (2013): "Spiders and snakes: offshoring and agglomeration in the global economy", Journal of International Economics, vol. 90(2), 245-254.

BLÁZQUEZ, L., DÍAZ-MORA, C. y GANDOY, R (2012). “EU Integration and Production Networks”, Revista de Economía Aplicada, no. 60 (vol. XX), 5-24.

CATTANEO, O., GEREFFI, G., MIROUDOT, S. and TAGLIONI, D. (2013): “Joining, upgrading and being competitive in global value chains", Policy Research Working Paper no. 6406, The World Bank.

CÓRCOLES, D., DÍAZ-MORA, C. and GANDOY, R. (2014): "Product sophistication: A tie that binds partners in international trade", Economic Modelling, vol. 44(1), S33-S41.

COSTINOT, A., VOGEL, J. and WANG, S. (2013): “An Elementary Theory of Global Supply Chains”, Review of Economic Studies, vol. 80, 109-144.

ESTEVADEORDAL, A., BLYDE, J. and SUOMINEN, K. (2013): "Are Global Value Chains Really Global? Policies to Accelerate Countries' Access to International Production Networks", paper presented at the E15 Expert Group on Global Value Chains.

HAUSMMAN, R., HAWANG, J. and RODRIK, D. (2007): "What you export matters", Journal of Economic Growth, vol. 12 (1), 1-25.

HAUSMMAN, R., HIDALGO, C.A., BUSTOS, S., COSCIA, M., CHUNG, J., JIMÉNEZ, A., SIMOES, A. and YILDIRIM, M.A. (2011): "The Atlas of Economic Complexity ", Puritan Press, Cambridge.

HELPMAN, E., MELITZ, M. and RUBINSTEIN, Y. (2008): "Estimating trade flows: trading partners and trading volumes", Quarterly Journal of Economics, vol. 123 (2), 441-487.

HIDALGO, C. A. (2009): "The dynamics of economic complexity and the product space over 42-year period", CID Working Paper 189.

HIDALGO, C. A. and HAUSMANN, R. (2009): "The Building Blocks of Economic Complexity", Proc. of National Academy of Science, vol. 106 (26), 10570-10575.

HUMPHREY, J. and SCHMITZ, H. (2002): "How does intersection in global value chains affect upgrading in industrial clusters?”, Regional Studies, vol. 36 (9), 1017-1027.

JONES, R. and KIERZKOWSKI, H. (1990): "The role of services in production and international trade: a theoretical framework", in Jones, R. and Krueger, A. (Eds), "The Political Economy of International Trade: Essays in Honour of Robert E. Baldwin", Cambridge.

KAREEM, F. O., MARTINEZ-ZARZOSO, I. and BRÜMMER, B. (2016): "Fitting the Gravity Model when Zero Trade Flows are Frequent: a Comparison of Estimation Techniques Using Africa's Trade Data", GlobalFood Discussion Papers 77, Georg-August-Universitaet Goettingen

LALL, S. WEISS, J. and ZHANG, J. (2006): "The sophistication of exports: A new measure of product characteristic", World Development, vol. 34, 222-237.

MILBERG, W. and WINKLER, D. (2010): "Trade crisis and recovering restructuring of global value chains", in Cattaneo, O., Gereffi, G., Staritz, C. (Eds.), "Global Value Chains in a Postcrisis World: a development perspective", The World Bank.

NG, F. and YEATS, A., (2001). "Production Sharing in East Asia: Who Does What for Whom and Why?", in Cheng, L. and Kierzkowski, H. (Eds), "Global Production and Trade in East Asia", Kluwer Academic, Boston.

REINSTALLER, A., HÖLZL, W., KUTSAM, J. and SCHMID, C. (2012): “The development of productive structures of EU Member States and their international competitiveness", European Commission, DG Enterprise and Industry and WIFO. 
SANTOS SILVA, J.M.C. and TENREYRO, S. (2006) "The log of gravity", The Review of Economics and Statistics, vol. 88, 641-658.

SIMOES, A. \& HIDALGO, C.A., (2011). The Economic Complexity Observatory: An Analytical Tool for Understanding the Dynamics of Economic Development. Workshops at the Twenty-Fifth AAAI Conference on Artificial Intelligence.

SUTTON, J. and TREFLER, D. (2011): "Deductions from the Export Basket: Capabilities, Wealth and Trade," NBER Working Papers 16834, National Bureau of Economic Research, Inc.

YEATS, A.J. (2001): "How Big is Global Production Sharing?" in Arndt, S.W. and Kierzkowski, H. (Eds.), "Fragmentation. New Production Patterns in the World Economy", Oxford University Press, Oxford.

\section{Figure 1: Export structure in EU countries groups by degree of complexity}

(Percentage of P\&C exports of each decile in total P\&C exports, 1995 and 2010)

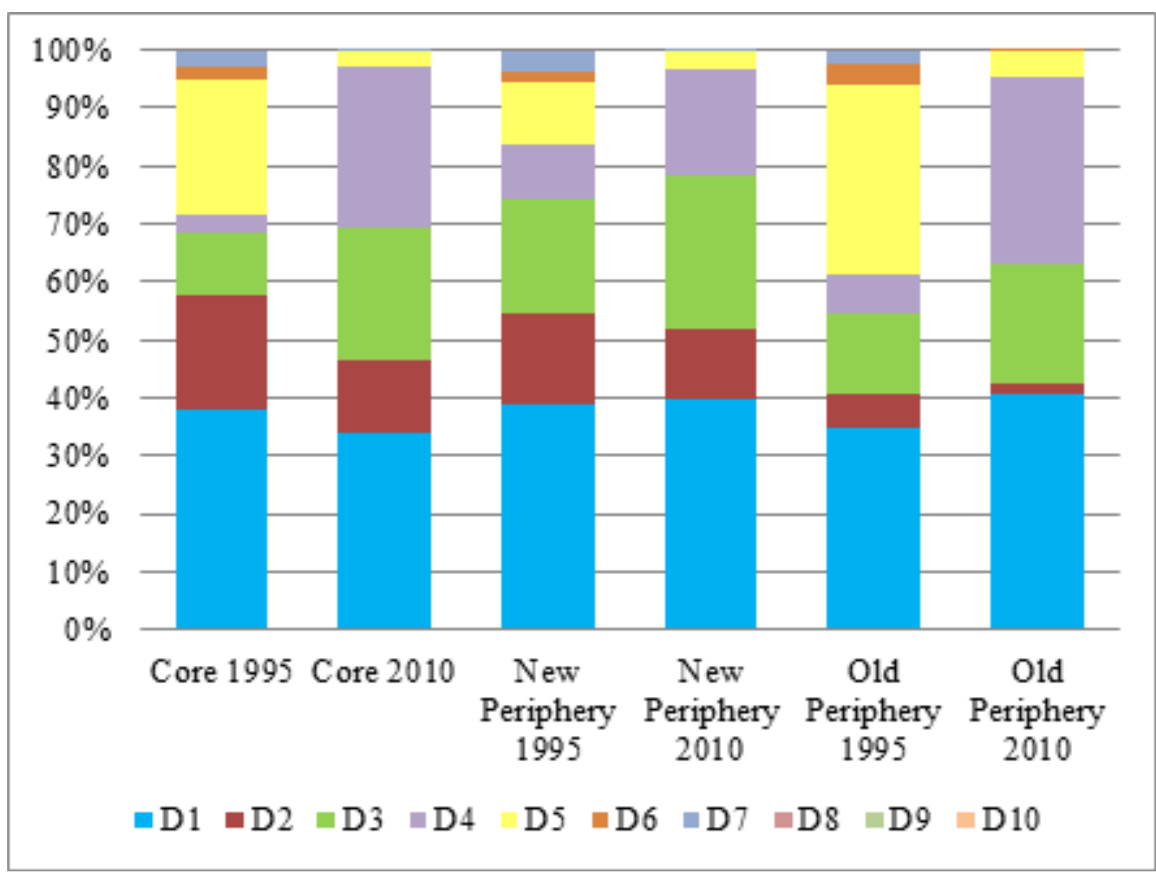

Note: Deciles are sorted from more complexity (D1) to less complexity (D10). The last three deciles are not shown in the chart because no P\&C item belongs to them.

Source: own elaboration from UN-Comtrade and data from the Atlas of Economic Complexity and the Observatory of Economic Complexity.

Figure 2: Export structure in EU countries by degree of complexity 
(Percentage of $\mathrm{P} \& \mathrm{C}$ exports of each decile in total $\mathrm{P} \& \mathrm{C}$ exports, 1995 and 2010)

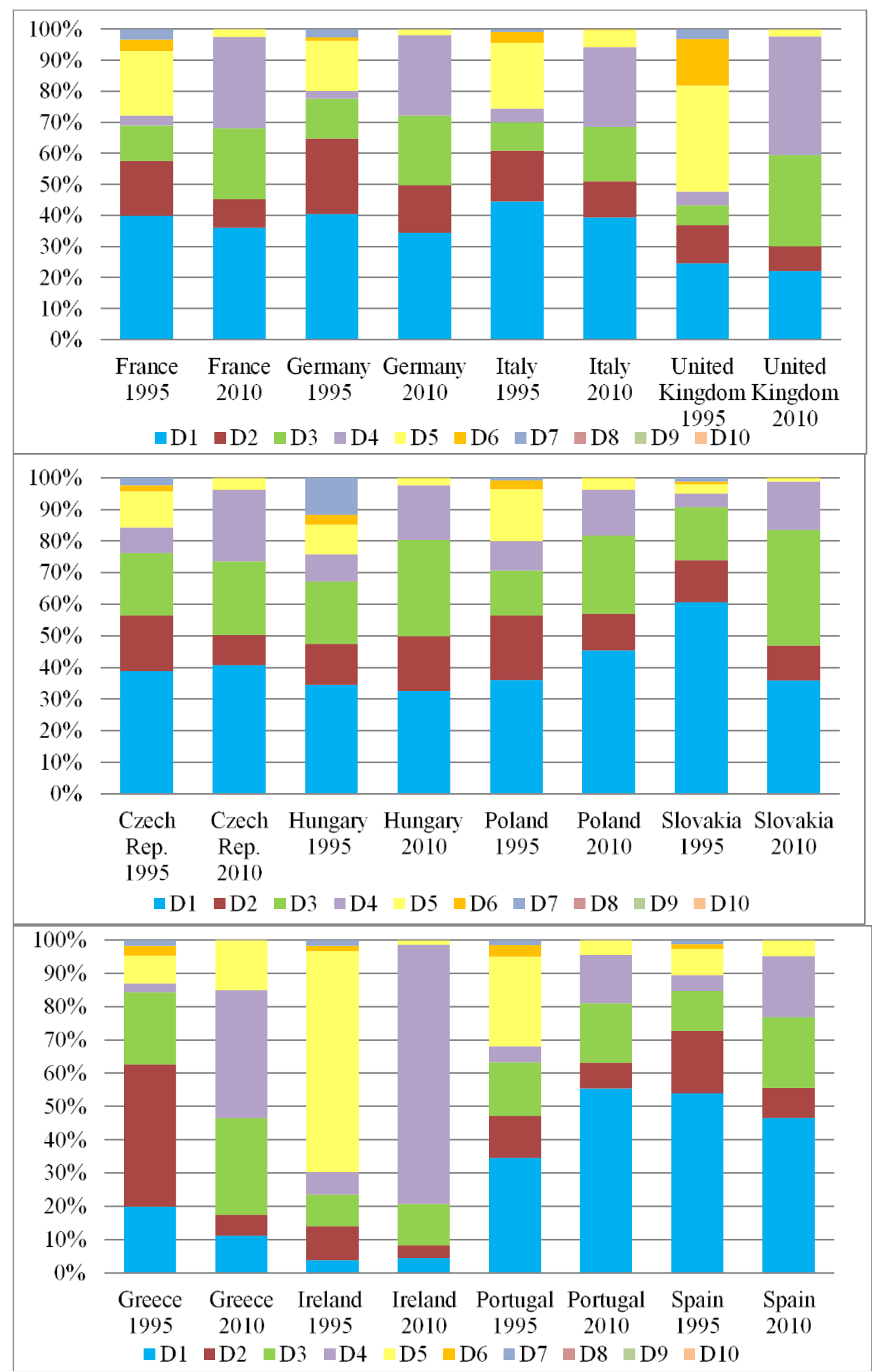

Note: Deciles are sorted from more complexity (D1) to less complexity (D10). The last three deciles are not shown in the chart because no P\&C item belongs to them.

Source: own elaboration from UN-Comtrade and data from the Atlas of Economic Complexity and the Observatory of Economic Complexity.

Table 1: OLS ESTIMATION RESULTS 


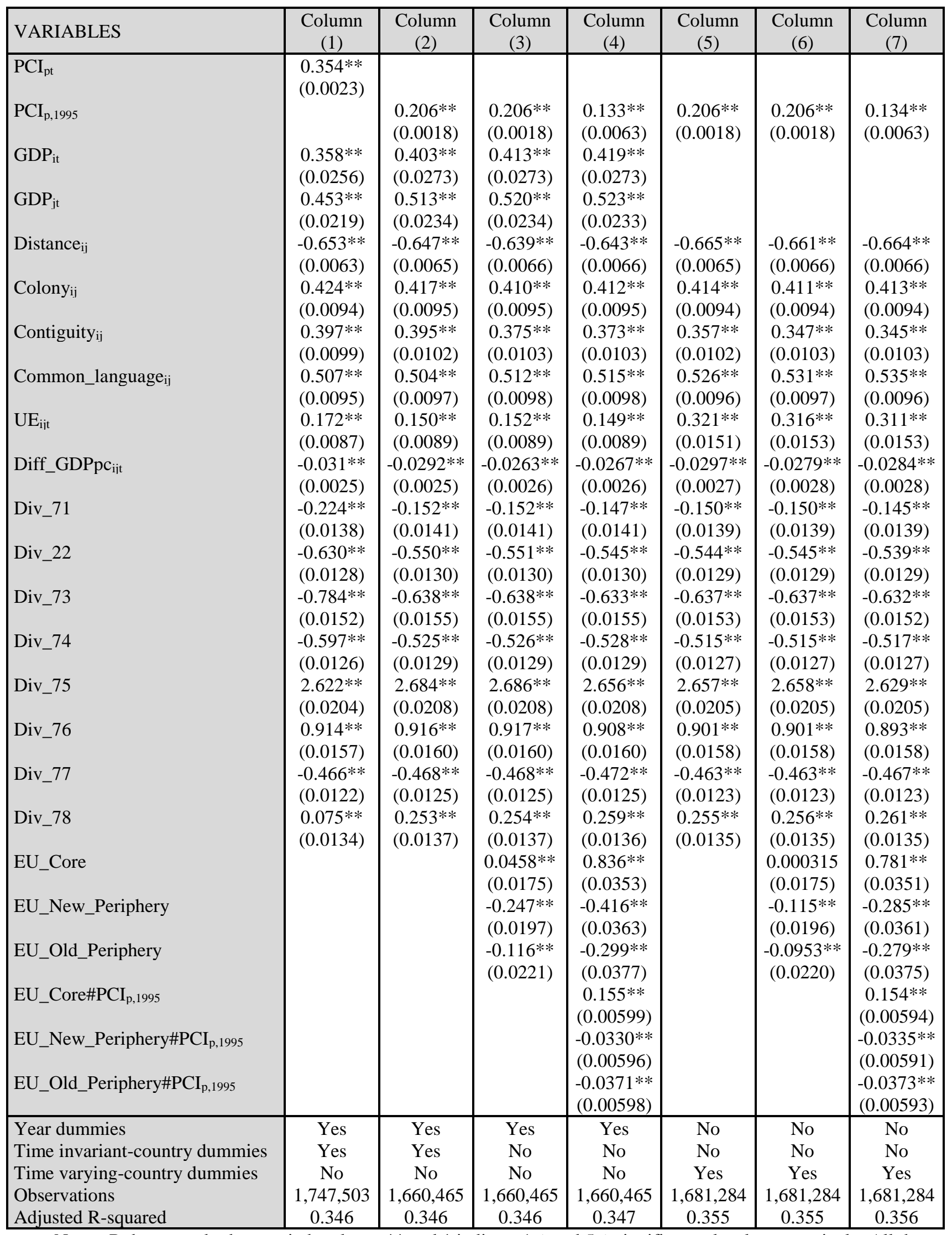

Notes: Robust standard errors in brackets. $* *$ and * indicate $1 \%$ and $5 \%$ significance levels, respectively. All the specifications include time, industry and country dummies. Time and country dummies are not reported for reasons of space. Column (1) includes all trade flows. Columns (2) to (7) exclude trade flows for 1995.

Table 2: HMR TWO-STAGE ESTIMATION RESULTS 


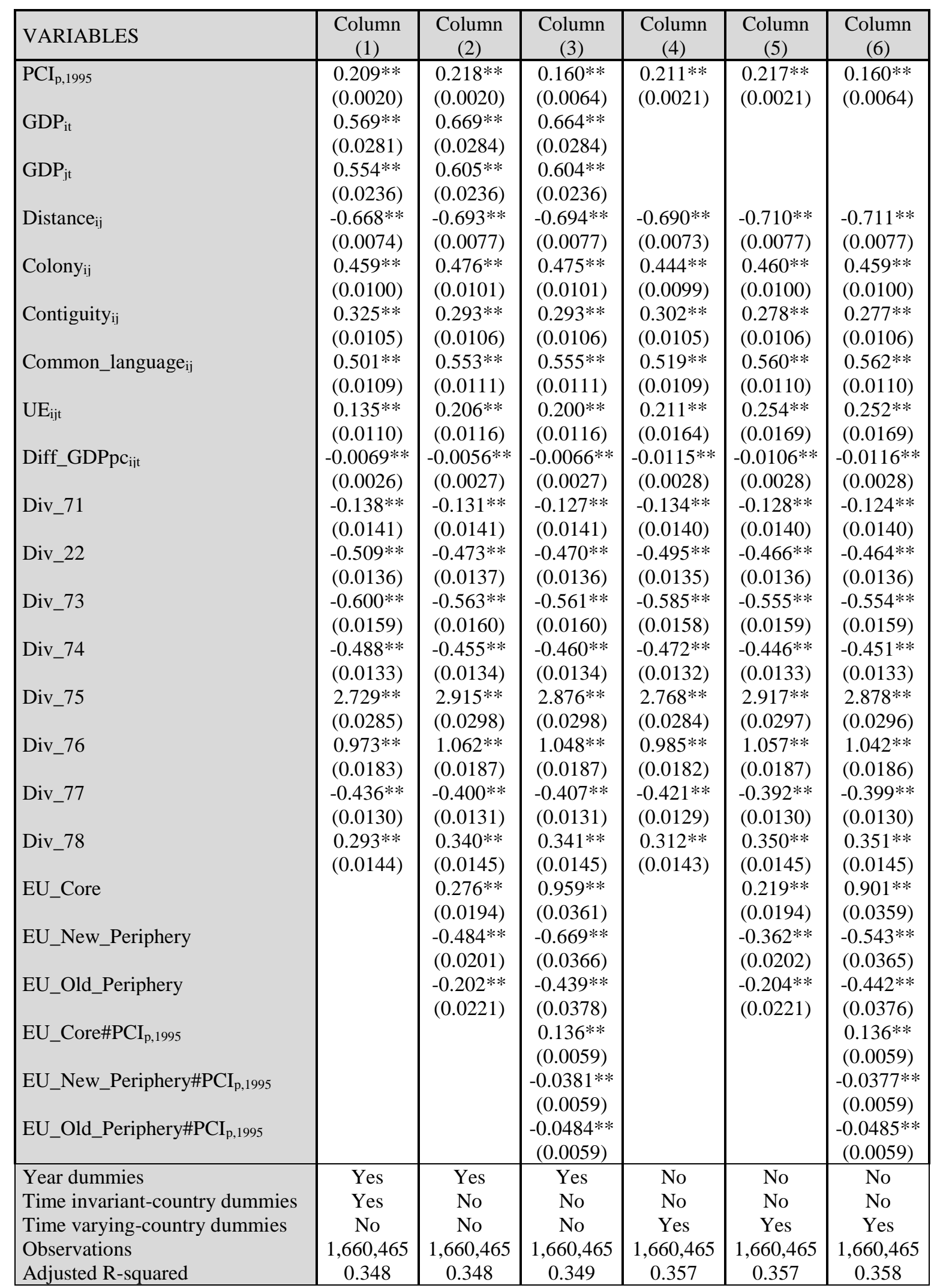

Notes: Robust standard errors in brackets. $* *$ and $*$ indicate $1 \%$ and $5 \%$ significance levels, respectively. All the specifications include time, industry and country dummies. Time and country dummies are not reported for reasons of space. All columns correspond to estimates for the second stage of the HMR two-step procedure. All columns exclude trade flows for 1995. 


\footnotetext{
${ }^{\mathrm{i}}$ Costinot et al. (2013) develop an elementary theory of global supply chains, distinguishing between different stages of a production process that is subject to mistakes at each stage. They predict that, in the case of simultaneous in addition to sequential production processes, richer countries with a lower probability of making mistakes will specialise in more complex parts where these mistakes would be more costly.

${ }^{\text {ii }}$ We use SITC Rev. 3, which disaggregates parts and components and final goods for the specific group 7 "Machinery and transport equipment," which accounts for one of the largest shares of global trade in goods (around 40\%). An alternative approach is to use recent statistical data based on international input-output tables, but its highly aggregated sectoral-level data is an important shortcoming.

iii A detailed explanation of the formula is available at http://atlas.cid.harvard.edu/about/glossary/.

${ }^{\text {iv }}$ Updated data are available at: http://atlas.cid.harvard.edu/rankings/product/.

${ }^{v}$ Updated data are available at: http://atlas.media.mit.edu/en/rankings/hs92/.

${ }^{\mathrm{vi}}$ It is important to note that the share of P\&Cs in total exports is different depending on the country, although it is quite similar across the countries considered. It is around 30 per cent for most of them. Three countries are exceptions: Ireland and the Czech Republic, where the figure is around 40 per cent and Greece, where it is hardly 20 per cent.

vii The results of the first stage probit regression of the two-step estimation procedure are omitted for reasons of space but are available on request.
} 